\title{
Arbeidsmarktprognoses Stedendriehoek en Noordwest Veluwe 2017-2022
}

Citation for published version (APA):

Peeters, T., \& Cörvers, F. (2018). Arbeidsmarktprognoses Stedendriehoek en Noordwest Veluwe 20172022. ROA. ROA Fact Sheets No. 008C https://doi.org/10.26481/umarof.2018008C

Document status and date:

Published: 01/01/2018

DOI:

10.26481/umarof.2018008C

Document Version:

Publisher's PDF, also known as Version of record

\section{Please check the document version of this publication:}

- A submitted manuscript is the version of the article upon submission and before peer-review. There can be important differences between the submitted version and the official published version of record.

People interested in the research are advised to contact the author for the final version of the publication, or visit the DOI to the publisher's website.

- The final author version and the galley proof are versions of the publication after peer review.

- The final published version features the final layout of the paper including the volume, issue and page numbers.

Link to publication

\footnotetext{
General rights rights.

- You may freely distribute the URL identifying the publication in the public portal. please follow below link for the End User Agreement:

www.umlib.nl/taverne-license

Take down policy

If you believe that this document breaches copyright please contact us at:

repository@maastrichtuniversity.nl

providing details and we will investigate your claim.
}

Copyright and moral rights for the publications made accessible in the public portal are retained by the authors and/or other copyright owners and it is a condition of accessing publications that users recognise and abide by the legal requirements associated with these

- Users may download and print one copy of any publication from the public portal for the purpose of private study or research.

- You may not further distribute the material or use it for any profit-making activity or commercial gain

If the publication is distributed under the terms of Article $25 \mathrm{fa}$ of the Dutch Copyright Act, indicated by the "Taverne" license above, 


\section{Arbeidsmarktprognoses Stedendriehoek en Noordwest Veluwe 2017-2022}

Tim Peeters

Frank Cörvers

\section{ROA Fact Sheet}

ROA-F-2018/8C

Researchcentrum voor Onderwijs en Arbeidsmarkt | ROA Research Centre For Education and the Labour Market / ROA 


\section{Arbeidsmarktprognoses Stedendriehoek en Noordwest Veluwe 2017-2022}

\section{Inleiding}

Als onderdeel van het Project Onderwijs-Arbeidsmarkt (POA) stelt het ROA sinds 2013 tweejaarlijkse regionale arbeidsmarktprognoses op die tegemoet komen aan de toenemende belangstelling voor regionale arbeidsmarktinformatie. Binnen dit kader past ook voorliggende factsheet met arbeidsmarktprognoses voor de arbeidsmarktregio Stedendriehoek en Noordwest Veluwe. Deze prognoses bestrijken de periode 20I7-2022 en worden weergegeven voor 24 opleidingscategorieën die verdeeld zijn over zes opleidingsniveaus. Waar mogelijk worden de prognoses vergeleken met deze voor Overijssel als geheel, en wordt eveneens een relatie gelegd met zowel de sectorals opleidingsspecialisatie van de werkgelegenheid in de verschillende regio's. ${ }^{.} \mathrm{Zie}$ ook Tekstbox I voor definities van de in deze factsheet gebruikte variabelen.

\section{Prognoses en actuele arbeidsmarktcijfers naar} opleidingsniveau

De bevolking van de arbeidsmarktregio Stedendriehoek en Noordwest Veluwe bevindt zich slechts voor $20 \%$ in Overijssel, waarmee het de kleinste van de drie constituerende arbeidsmarktregio's is. Tabel I geeft voor deze regio de huidige arbeidsmarktsituatie weer per opleidingscategorie, evenals de prognoses die de komende zes jaar verwacht worden. Ondanks het beperkte bevolkingsaandeel dat binnen de provincie Overijssel valt, verschillen de voorspellingen en actuele cijfers voor beide regio's niet erg veel van elkaar.

Schoolverlaters en werkzoekenden van mbo $2 / 3$ en mbo 4 hebben een matige ITA-typering, voornamelijk als gevolg van een betrekkelijk hoge voorziene jaarlijkse arbeidsmarktinstroom. Een lage instroom en hoge vervangingsvraag zorgen dan weer voor goede arbeidsmarktperspectieven voor schoolverlaters van basisonderwijs/vmbo en wo. Voor wo is de instroom met gemiddeld 2,I\% per jaar tevens duidelijk lager dan deze in Twente (3,2\%) en Regio Zwolle (3,3\%). Ook voor havo/vwo zijn de prognoses goed, hetgeen eveneens resulteert uit een relatief lage instroom (gemiddeld I, $6 \%$ per jaar). Met een ITA van exact I zullen havo- en vwo-gediplomeerden het bovendien naar verwachting in deze arbeidsmarktregio beter doen dan in Overijssel als geheel $(\mathrm{I}, \mathrm{O} 4)$. Voor de drie laagste

I Voor de arbeidsmarktontwikkelingen van de hele provincie Overijssel, zie de factsheet met nummer ROA-F-20I8/8. opleidingsniveaus is de werkloosheid tevens aanmerkelijk kleiner dan in Overijssel (gemiddeld o,8\%-punten minder).

Opvallend is dat de verwachte ITA voor basisonderwijs en vmbo even gunstig is als voor wo (beiden 0,92). Beide opleidingsniveaus kennen een vrij grote vervangingsvraag en relatief kleine arbeidsmarktinstroom (bij basisonderwijs en vmbo gaat het veelal om voortijdig schoolverlaters van vmbo, mbo of havo/vwo). Deze gunstige perspectieven dienen echter met enige voorzichtigheid geïnterpreteerd te worden. Een aanzienlijk deel van de vraag naar personen met basisonderwijs of vmbo als opleidingsachtergrond heeft namelijk betrekking op kleine banen. Dit kan afgeleid worden van het relatief lage gemiddeld aantal gewerkte uren per week $(26,5)$ en het hoge aandeel van studenten en scholieren (24\%). Bovendien gaat het vaak om flexibele banen met weinig doorgroeimogelijkheden. Enerzijds blijkt dit uit het lage percentage dat voltijds en vast in dienst is. Anderzijds komt dit ook tot uiting in het slechte loopbaanperspectief. De variabele "typering loopbaan", die per opleidingsniveau de loongroei tussen ca. 25 en 45 jaar (berekend voor Nederland als geheel) weergeeft in 2016, is namelijk het minst gunstig voor laagopgeleiden, en het meest gunstig voor havo/vwo. ${ }^{2}$ Deze laatste groep bestaat mogelijk deels uit mensen die geen hogere opleiding hebben afgemaakt omdat ze door hun persoonlijke capaciteiten uitstekende kansen op de arbeidsmarkt hadden.

Verder is van belang dat de groep van laagopgeleiden met basisonderwijs of vmbo heel heterogeen is: niet alleen scholieren, maar ook voortijdig schoolverlaters zonder startkwalificatie (minimaal mbo 2 of havo), schoolverlaters van het speciaal onderwijs en arbeidsgehandicapten. Bij het aangegeven goede arbeidsmarktperspectief is geen rekening gehouden met de mogelijke sociale, fysieke en cognitieve beperkingen van mensen binnen deze groep.

\section{Sectorspecialisatie}

Zoals uit blijkt uit Figuur I bestaan er met betrekking tot de sectorspecialisatie enkele opvallende verschillen tussen Overijssel en de arbeidsmarktregio Stedendriehoek en Noordwest Veluwe. Zo is deze arbeidsmarktregio niet gespecialiseerd in landbouw, bosbouw en visserij ten opzichte van Nederland of Overijssel. Hetzelfde geldt voor de metaalindustrie en de chemische industrie, waarin voornamelijk Twente relatief veel werkenden kent. Wel is er

2 De indicator voor loopbaanperspectief wordt berekend aan de hand van het verschil in bruto uurloon van werkenden in de leeftijdsgroep 20-29 jaar en 40-49 jaar. Voor een argumentatie, zie Fouarge, D., Kriechel, B., \& Dohmen, T. (2014), Occupational sorting of school graduates: The role of economic preferences, Journal of Economic Behavior \& Organization, 106, 335-351. 
Tabel 1

Arbeidsmarktprognoses (2017-2022) en actuele arbeidsmarktcijfers (2015-2016) Stedendriehoek en Noordwest Veluwe naar opleidingsniveau

\begin{tabular}{|c|c|c|c|c|c|c|c|}
\hline & bo/vmbo & havo/vwo & mbo $2 / 3$ & mbo 4 & hbo & wo & totaal \\
\hline \multicolumn{8}{|l|}{ Prognoses } \\
\hline Uitbreidingsvraag (\%) & 0,6 & 0,6 & 0,8 & 0,7 & 0,6 & 0,9 & 0,7 \\
\hline Vervangingsvraag (\%) & 3,6 & 1,8 & 2,7 & 1,9 & 2,9 & 3,5 & 2,9 \\
\hline Arbeidsmarktinstroom (\%) & 1,9 & 1,6 & 4,6 & 3,4 & 3,0 & 2,1 & 2,9 \\
\hline ITA & 0,92 & 1,00 & 1,10 & 1,08 & 1,01 & 0,92 & 1,00 \\
\hline Typering ITA & goed & goed & matig & matig & redelijk & goed & goed \\
\hline Typering loopbaan (euro) & slecht & zeer goed & matig & redelijk & redelijk & goed & -- \\
\hline \multicolumn{8}{|l|}{ Actuele indicatoren } \\
\hline Bruto uurloon (euro) ${ }^{* *}$ & 13,7 & 17,3 & 17,7 & 19,2 & 25,1 & 34,7 & -- \\
\hline Werkenden & 13.000 & 4.000 & 10.000 & 11.000 & 13.000 & 5.500 & 57.000 \\
\hline Werkzaamheid (\%) & 48 & 59 & 64 & 77 & 79 & 83 & 65 \\
\hline Werkloosheid (\%) & 5 & 5 & 4 & 5 & 3 & 3 & 4 \\
\hline Vast werk (\%) & 67 & 63 & 85 & 89 & 90 & 94 & 82 \\
\hline Voltijds (\%) & 43 & 35 & 51 & 51 & 52 & 63 & 49 \\
\hline Wekelijkse arbeidsduur (uur) & 26,5 & 24,3 & 31,8 & 31,9 & 32,8 & 35,2 & 30,6 \\
\hline Leeftijd werkenden (jaar) & 39,3 & 36,3 & 42,3 & 41,6 & 41,7 & 44,8 & 41,2 \\
\hline Student/scholier (\%) & 24 & 31 & 2 & 4 & 1 & 0 & 9 \\
\hline
\end{tabular}

"Prognoses als gemiddeld jaarlijks percentage van de werkzame beroepsbevolking in 2016; actuele indicatoren als percentage van de werkzame, totale of potentiële beroepsbevolking 2015-2016 (zie Tekstbox 1), tenzij anders aangegeven

Lonen voor Nederland in 2016

Figuur 1

Sectorspecialisatie Stedendriehoek en Noordwest Veluwe ten opzichte van Nederland (2015-2016)

Landbouw, bosbouw en visserii Voedings- en genotmiddelenindustrie Chemische industrie

Metaalindustrie

Overige industrie

Energie

Bouwnijverheid

Detailhandel

Groothandel

Vervoer en opslag

Horeca

nformatie en comm unicatie

Financiële dienstverlening en onroerend goed

Specialistische zakelijke dienstverlening

Verhuur en overige zakelijke dienstverlening

Openbaar bestuur en overheidsdiensten

Onderwijs

Welzijin

Cultuur sport en recreatie

Overige dienstverlening, huishoudens en

extraterritoriale organisaties

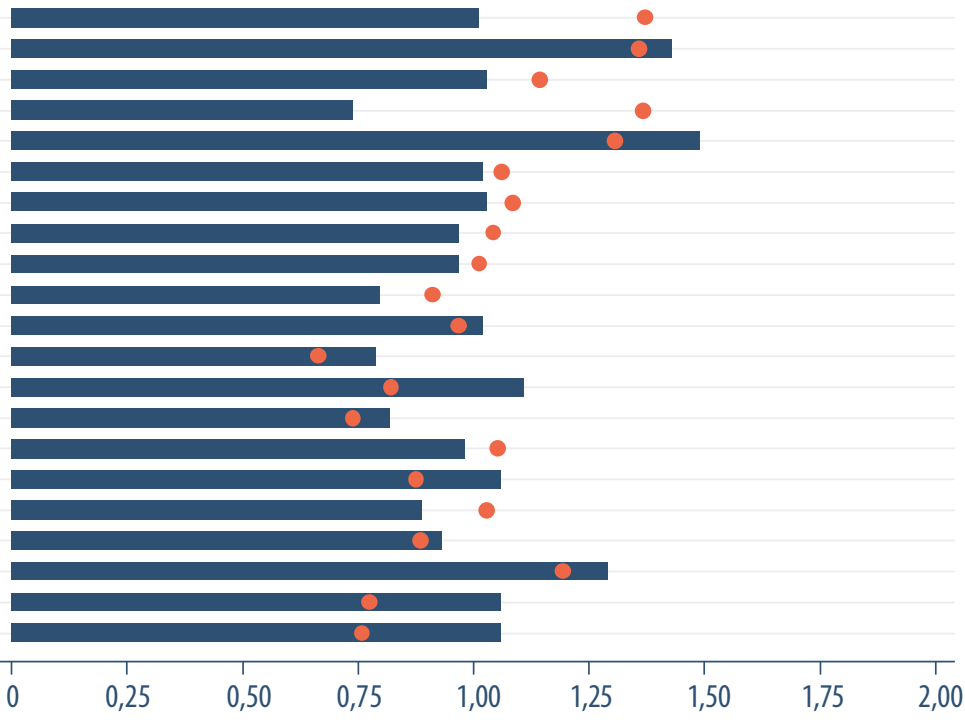

Sectorspecialisatie Stedendriehoek en Noordwest Veluwe Sectorspecialisatie Overijsse 
Tekstbox 1 Definities kernbegrippen

\begin{tabular}{|c|c|}
\hline Variabele & Definitie \\
\hline Uitbreidingsvraag & $\begin{array}{l}\text { Vraag naar nieuwe arbeidskrachten die ontstaat door de groei van de werkgelegenheid. Als er sprake is van een werkgelegenheidsdaling, is de } \\
\text { uitbreidingsvraag negatief. }\end{array}$ \\
\hline Vervangingsvraag & $\begin{array}{l}\text { Vervangingsvraag is de vraag naar nieuwe arbeidskrachten die ontstaat door bijvoorbeeld pensionering, (tijdelijke) uittreding vanwege zorgtaken, } \\
\text { arbeidsongeschiktheid, beroepsmobiliteit of doorstroom naar een andere opleiding. }\end{array}$ \\
\hline Arbeidsmarktuitstroom & De som van de vervangingsvraag en de negatieve uitbreidingsvraag. \\
\hline Arbeidsmarktinstroom & $\begin{array}{l}\text { De arbeidsmarktinstroom is het verwachte aanbod van nieuwe arbeidskrachten op de arbeidsmarkt. Deze is gebaseerd op de verwachte uitstroom van } \\
\text { schoolverlaters uit het initiële dag-, deeltijd-, niet-reguliere voltijdonderwijs en de beroepsgerichte volwasseneneducatie. Het weergegeven aanbod in de } \\
\text { figuren } 2 \text { en } 3 \text { is de instroom. Gecorrigeerd voor mobiliteitsstromen tussen arbeidsmarktregio's. }\end{array}$ \\
\hline Baanopeningen & $\begin{array}{l}\text { Baanopeningen zijn de totale vraag naar nieuwkomers op de arbeidsmarkt, zoals deze is bepaald door de werkgelegenheidsgroei (positieve uitbreidingsvraag) } \\
\text { en de vervangingsvraag. In de figuren } 2 \text { en } 3 \text { is dit de vraag naar arbeid. }\end{array}$ \\
\hline ITA & $\begin{array}{l}\text { Indicator Toekomstige Arbeidsmarktperspectief (ITA) van schoolverlaters en werkzoekenden. Deze indicator is gelijk aan een deling van het verwachte aanbod } \\
\text { door de verwachte vraag tot 2022. Naarmate de waarde van de ITA hoger ligt, is er sprake van een slechter arbeidsmarktperspectief. Een waarde tussen 1,01 en } \\
1,05 \text { duidt op een evenwichtssituatie. }\end{array}$ \\
\hline Typering ITA & $\begin{array}{l}\text { Een kwalitatieve beschrijving van de ITA. ITA } \leq 0,85 \text { wordt als "zeer goed" getypeerd, ITA }>0,85 \text { en } \leq 1,00 \text { als "goed", ITA > 1,00 en } \leq 1,05 \text { als "redelijk", ITA > } \\
1,05 \text { en } \leq 1,15 \text { als "matig" en ITA }>1,15 \text { als "slecht". }\end{array}$ \\
\hline Typering loopbaan & $\begin{array}{l}\text { Het bruto uurloon van werkenden in de leeftijdsgroep } 40-49 \text { jaar ten opzichte van het bruto uurloon van werkenden in de leeftijdsgroep } 20-29 \text { jaar. Gemiddelde } \\
\text { cijfers voor Nederland in } 2016 \text {. }\end{array}$ \\
\hline Bruto uurloon & $\begin{array}{l}\text { Gemiddeld bruto uurloon van werknemers in euro's. Enquête Beroepsbevolking (EBB) gekoppeld aan het Sociaal Statistisch Bestand (SSB) van het jaar } 2016 . \\
\text { Gemiddelde cijfers voor Nederland in } 2016 .\end{array}$ \\
\hline Werkenden & Minimaal 1 uur werkzaam per week en in de leeftijd 15-74. Cijfers op basis van de Enquête Beroepsbevolking van het CBS. \\
\hline Werkzaamheid & Het percentage werkzaam is de werkzame beroepsbevolking als percentage van de potentiële beroepsbevolking (iedereen ouder dan 15 en jonger dan 75 jaar). \\
\hline Werkloosheid & $\begin{array}{l}\text { Percentage personen die geen betaald werk hebben, wel recent hebben gezocht en daarvoor direct beschikbaar zijn als percentage van de totale } \\
\text { beroepsbevolking (werkzaam en werkloos). }\end{array}$ \\
\hline Vast werk & Personen met een vast dienstverband. Percentage op basis van werknemers in de werkzame beroepsbevolking. \\
\hline Voltijds & Voltijdarbeid betreft personen die minstens 35 uur per week werkzaam zijn. Percentage op basis van de werkzame beroepsbevolking. \\
\hline Leeftijd & Gemiddelde leeftijd. \\
\hline Uren & Gemiddeld aantal uren werk per week. \\
\hline Student/scholier & Percentage van de werkenden met maatschappelijke positie student/scholier. \\
\hline Sectorspecialisatie & $\begin{array}{l}\text { De verhouding tussen het aandeel van het aantal werkenden in een sector in een bepaalde regio ten opzichte van het aandeel van die sector in Nederland. Een } \\
\text { sectorspecialisatiecoëfficiënt groter dan } 1 \text { impliceert dat het aandeel werkenden in de desbetreffende sector in de regio groter is dan in Nederland als geheel. }\end{array}$ \\
\hline Opleidingsspecialisatie & $\begin{array}{l}\text { De ratio van het aandeel personen met een bepaalde opleidingscategorie die wonen in een bepaalde regio ten opzichte van het aandeel van die } \\
\text { opleidingscategorie in het Nederlandse totaal. Indien de specialisatiecoëfficiënt voor een opleidingscategorie groter is dan 1, betekent dit dat de regio in } \\
\text { verhouding tot Nederland een groter aandeel van mensen met deze opleiding kent. }\end{array}$ \\
\hline
\end{tabular}


in Stedendriehoek en Noordwest Veluwe een relatief grote werkgelegenheid in de voedings- en genotmiddelenindustrie en de overige industrie in verhouding tot de Nederlandse sectorstructuur. Ook de welzijnssector en (in mindere mate) de sector financiële dienstverlening en onroerend goed kennen een sectorspecialisatiecoëfficiënt die groter is dan I.

\section{Perspectieven naar opleidingscategorie}

Figuren 2 en 3 tonen de geschatte verhouding tussen vraag en aanbod voor de opleidingscategorieën binnen respectievelijk het lager/middelbaar en hoger onderwijs tijdens de komende zes jaar. Binnen het lager- en middelbaar onderwijs worden gemiddeld goede arbeidsmarktperspectieven verwacht voor schoolverlaters van basisonderwijs/vmbo, havo/ vwo en mbo 4 techniek. Slechte perspectieven worden daarentegen voorzien voor mbo $2 / 3$ groen en mbo $2 / 3$ economie, die beide gekenmerkt worden door een vrij groot arbeidsaanbod. Mbo 2/3 economie wijkt hiermee sterk af van de prognoses voor Twente en Regio Zwolle, waar de vooruitzichten voor deze opleidingscategorie significant beter zijn (hoewel nog steeds matig) door een aanzienlijk lager arbeidsaanbod. De meeste wo-categorieën kennen minstens goede perspectieven, met wo landbouw en natuur en wo techniek als koplopers (zeer goed). Als gevolg van een vrij lage vraag heeft wo taal en cultuur binnen Overijssel enkel in Stedendriehoek en Noordwest Veluwe redelijke in plaats van goede perspectieven. De verwachtingen voor hbo zijn eerder gemengd, met matige perspectieven voor hbo economie en hbo gedrag en maatschappij.

De voedings- en genotmiddelenindustrie en de overige industrie, sectoren waarin Stedendriehoek en Noordwest Veluwe een relatief grote werkgelegenheid kent, worden verwacht knelpunten te ondervinden bij het invullen van technische vacatures op alle niveaus behalve mbo $2 / 3$. Dit geldt niet voor economische vacatures in de sector financiële dienstverlening en onroerend goed. Binnen de economische opleidingen heeft namelijk enkel wo economie en recht goede arbeidsmarktperspectieven voor afgestudeerden in Stedendriehoek en Noordwest Veluwe.

\section{Relatie arbeidsmarktperspectieven en specialisatie naar opleiding}

Het verband tussen de ITA en de mate van specialisatie per opleiding, weergegeven in Figuur 4, is iets minder positief lineair dan voor Twente en Overijssel. Sommige opleidingen hebben namelijk een lage specialisatie maar toch een relatief ongunstige ITA, zoals hbo en wo taal en cultuur. Ook voor mbo $2 / 3$ economie en mbo $2 / 3$ groen valt op dat beiden een zeer hoge ITA hebben maar toch verhoudingsgewijs minder voorkomen in deze arbeidsmarktregio dan in
Nederland. Mbo 4 zorg en welzijn is de categorie met de grootste specialisatie, wat deels samenhangt met de relatieve specialisatie in de welzijnssector (zie Figuur I). Net zoals mbo $2 / 3$ zorg en welzijn heeft deze opleiding echter slechts matige arbeidsmarktperspectieven. De zwakste perspectieven op hbo-niveau gelden voor de categorieën hbo gedrag en maatschappij en hbo economie, die in deze arbeidsmarktregio tevens verhoudingsgewijs meer gediplomeerden tellen dan in Nederland. Het omgekeerde geldt voor wo gedrag en maatschappij, die een zeer gunstige ITA heeft en relatief weinig voorkomt in deze regio.

\section{Conclusie}

Ondanks de beperkte regionale overlap tussen de arbeidsmarktregio Stedendriehoek en Noordwest Veluwe en Overijssel, zijn de prognoses en actuele arbeidsmarktindicatoren van beide regio's vrij gelijkaardig. Als gevolg van een vrij hoge arbeidsmarktinstroom worden voor mbo $2 / 3$ en mbo 4 tot 2022 slechts matige arbeidsmarktperspectieven verwacht. Wo-schoolverlaters kennen daarentegen goede vooruitzichten, wat hoofdzakelijk een gevolg is van een betrekkelijk lage verwachte instroom. Verder zijn personen afkomstig van het basisonderwijs/ vmbo en havo/vwo in deze arbeidsmarktregio minder vaak werkzaam dan in Nederland als geheel.

Binnen het middelbaar onderwijs gelden de beste arbeidsmarktperspectieven in Stedendriehoek en Noordwest Veluwe voor mbo 4 techniek, en de slechtste voor mbo $2 / 3$ groen en mbo $2 / 3$ economie. De opleidingscategorieën binnen het wo kennen overwegend goede of zeer goede vooruitzichten, terwijl deze binnen het hbo eerder gemengd zijn. Knelpunten worden verwacht voor technische vacatures in de industriesectoren, behalve voor schoolverlaters van mbo 2/3 techniek. Bij economische vacatures worden daarentegen weinig rekruteringsproblemen verwacht, aangezien voor de meeste opleidingsniveaus een aanbodoverschot van economisch geschoolden wordt voorzien. 


\section{Figuur 2}

Vraag en aanbod voor opleidingscategorieën lager/middelbaar (beroeps)onderwijs, Stedendriehoek en Noordwest Veluwe (2017-2022)

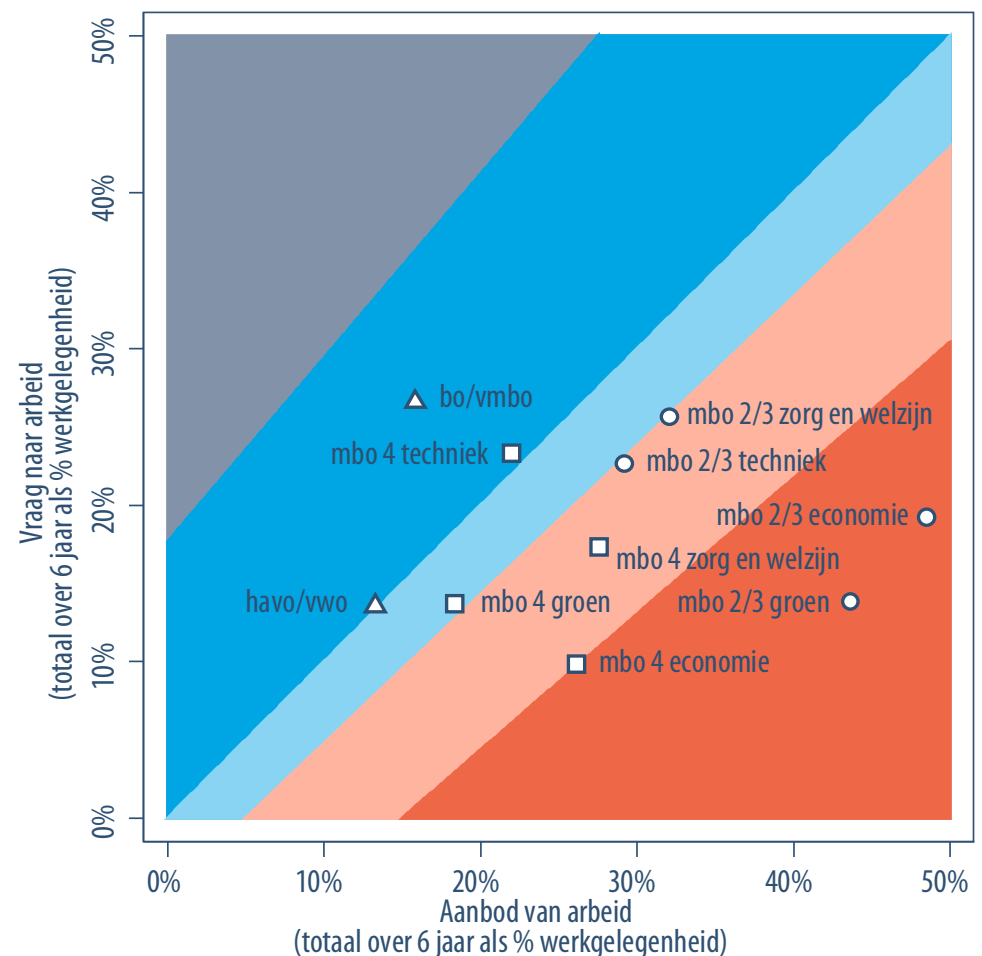

\begin{tabular}{|c|c|}
\hline & ITA-typering zeer goed \\
\hline & ITA-typering goed \\
\hline & ITA-typering redelijk \\
\hline & ITA-typering matig \\
\hline & ITA-typering slecht \\
\hline$\Delta$ & bo/vmbo en havo/vwo \\
\hline 0 & mbo $2 / 3$ \\
\hline 口 & mbo 4 \\
\hline
\end{tabular}

Figuur 3

Vraag en aanbod voor opleidingscategorieën hoger onderwijs, Stedendriehoek en Noordwest Veluwe (2017-2022)

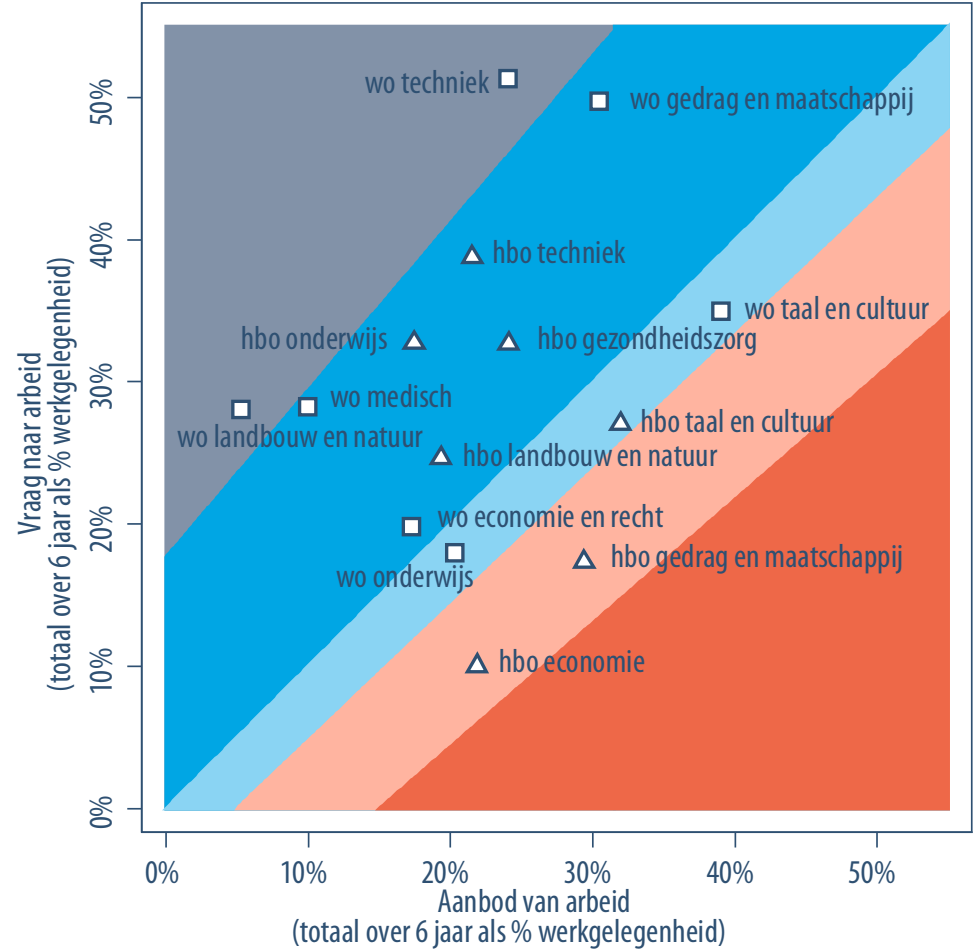

\begin{tabular}{|cl|}
\hline & ITA-typering zeer goed \\
\hline & ITA-typering goed \\
& ITA-typering redelijk \\
& ITA-typering matig \\
& ITA-typering slecht \\
$\Delta$ & hbo \\
$\mathbf{\Delta}$ & wo \\
\hline
\end{tabular}

(totaal over 6 jaar als \% werkgelegenheid) 


\section{Figuur 4}

Arbeidsmarktperspectieven (ITA) versus specialisatie naar opleidingscategorie, Stedendriehoek en Noordwest Veluwe

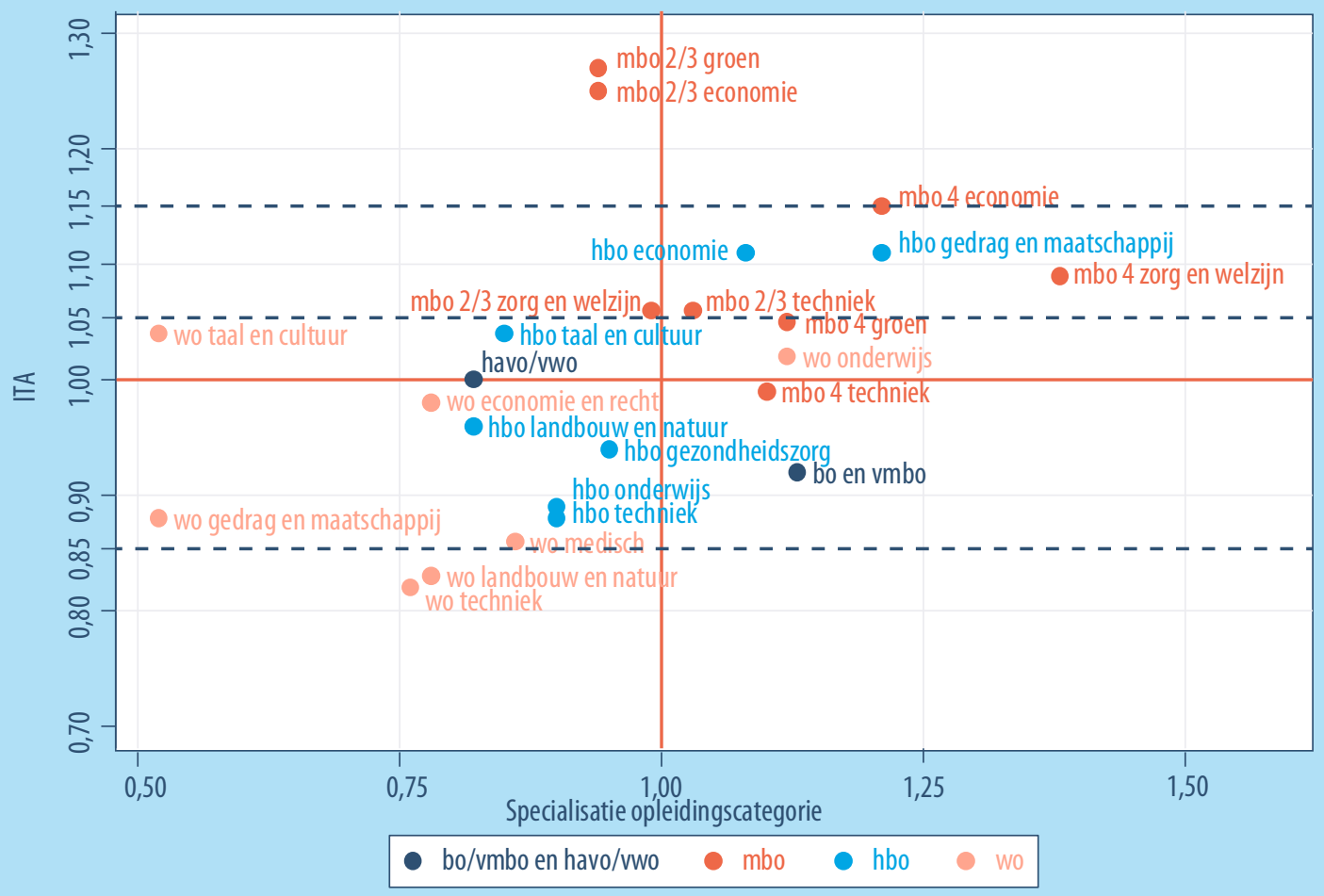




\section{Colofon}

( ) Researchcentrum voor Onderwijs en Arbeidsmarkt Niets uit deze uitgave mag op enige manier worden verveelvoudigd zonder voorafgaande schriftelijke toestemming van de directeur van het ROA.

Researchcentrum voor Onderwijs en Arbeidsmarkt

Maastricht University

School of Business and Economics

secretary-roa-sbe@maastrichtuniversity.nl

www.roa.n

\section{Vormgeving}

ROA secretariaat, Maastricht

maart 2018 